\title{
Effect on non-vascular outcomes of lowering LDL cholesterol in patients with chronic kidney disease: results from the Study of Heart and Renal Protection
}

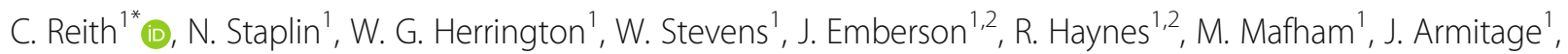
A. Cass ${ }^{3}$, J. C. Craig ${ }^{4}$, L. Jiang ${ }^{5}$, T. Pedersen ${ }^{6,7}$, C. Baigent ${ }^{1,2}$, M. J. Landray ${ }^{1}$, on behalf of the SHARP Collaborative Group

\begin{abstract}
Background: Reducing LDL cholesterol (LDL-C) with statin-based therapy reduces the risk of major atherosclerotic events among patients with chronic kidney disease (CKD), with no evidence of an excess risk of cancer or death from any non-vascular cause. However, non-randomized data have suggested that statin therapy may have effects (both adverse and beneficial) on particular non-vascular conditions that do not cause death.

Methods: The Study of Heart and Renal Protection (SHARP) randomized patients with CKD to simvastatin $20 \mathrm{mg}$ plus ezetimibe $10 \mathrm{mg}$ (simvastatin/ezetimibe) daily versus matching placebo. Participants were followed up at least 6 monthly and all post-randomization serious adverse events (SAEs) were recorded. This supplementary analysis reports the effects of treatment on non-vascular SAEs, overall, by system of disease, by baseline characteristics, and by duration of follow-up.

Results: During a median of 4.9 years follow-up, similar numbers of participants in the two groups experienced at least one non-vascular SAE (3551 [76.4\%] simvastatin/ezetimibe vs 3537 [76.6\%] placebo; risk ratio [RR] 0.99, 95\% confidence interval $[\mathrm{Cl}]$ 0.95-1.04). There was no good evidence of any significant effect of simvastatin/ezetimibe on SAEs attributed to any particular nonvascular disease system (of 43 comparisons, only 3 yielded an uncorrected $p$ value $<0.05$, of which the smallest was $p=0.02$ ). The relative risk of any nonvascular SAE did not vary significantly among particular prognostic subgroups or by duration of follow-up.
\end{abstract}

Conclusions: In the SHARP trial, allocation to simvastatin/ezetimibe combination therapy was not associated with any significant non-vascular hazard.

Trials registration: SHARP was retrospectively registered after the first participant was enrolled in 2003 at ISRCTN (ISRCTN54137607 on 31 January 2005: http://www.isrctn.com/ISRCTN54137607) and ClinicalTrials.gov (NCT00125593 on 29 July 2005: https://clinicaltrials.gov/ct2/show/NCT00125593).

\footnotetext{
* Correspondence: christina.reith@ndph.ox.ac.uk

'Nuffield Department of Population Health (NDPH), University of Oxford,

Oxford, UK

Full list of author information is available at the end of the article
} 


\section{Background}

Meta-analyses of individual participant data from large randomized controlled trials have shown that statin therapy reduces the risk of major vascular events (defined as myocardial infarction (MI), coronary death, stroke or coronary revascularization) by about one fifth per $\mathrm{mmol} / \mathrm{L}(40 \mathrm{mg} / \mathrm{dL})$ reduction in low-density lipoprotein cholesterol (LDL-C), without any increase in the risk of non-vascular causes of death or of site-specific cancer [1-3]. Benefits have been demonstrated in a wide range of people with pre-existing vascular disease and diabetes [4], as well as in those with no prior history of vascular disease [5].

Chronic kidney disease (CKD) is associated with a significantly increased risk of cardiovascular disease (CVD), with premature CVD being a leading cause of death in people with CKD [6]. Several randomized placebocontrolled trials have tested the effects of lowering LDL-C with statin-based therapy in patients with CKD [7-9]. The Study of Heart and Renal Protection (SHARP) was the largest such trial, being conducted among over 9400 patients. In SHARP, allocation to the combination of simvastatin $20 \mathrm{mg}$ plus ezetimibe $10 \mathrm{mg}$ (simvastatin/ezetimibe) reduced major atherosclerotic events (MAEs), defined as non-fatal MI or coronary death, non-haemorrhagic stroke, or any arterial revascularization procedure, by 17\% (95\% confidence interval [CI] 6-26\%; $p=0.0021$ ) [9]. This reduction was achieved without any significant increase in any of the prespecified safety outcomes [10] of: muscle pain; elevation of creatine kinase (CK) to five to ten times the upper limit of normal (ULN) or greater than ten times the ULN; complications of gallstones and persistent elevation of liver transaminases to greater than three times the ULN. There were very few cases of the pre-specified outcome of myopathy (9 [0.2\%] simvastatin/ ezetimibe vs 5 [0.1\%] placebo) or of more severe cases of rhabdomyolysis (4 [0.1\%] simvastatin/ezetimibe vs 1 [0.0\%] placebo), and there was no significant excess risk of cancer or of death from any non-vascular cause [9].

In populations without CKD, large randomized trials, and meta-analyses of those trials, have shown that statins cause small increases in the risk of myopathy [11-13], diabetes [13-15], and probably haemorrhagic stroke [2, 13, 16]. However, reports from non-randomized observational studies (which are susceptible to bias) have also suggested that statin use is associated with higher rates of a wide range of other adverse events, including hepatic dysfunction [17, 18], acute kidney injury [17, 19], impaired cognition [20] and sleep disturbance [21]. Conversely, there have also been reports from such studies of associations between statin use and lower rates of some non-vascular events, including respiratory infections [22, 23], gastrointestinal bleeding [24], Parkinson's disease [25, 26] and fractures [27].
Patients with CKD are typically at higher risk of nonvascular events than the general population due to their potential for comorbid disease in association with renal impairment [28], hence it is important to assess whether statin-based therapy yields increases or decreases in the risks of other types of outcome. Such an assessment is most reliably achieved by analysis of large-scale randomized trials, and the aim of the present paper is to conduct such analyses in the SHARP trial, in which all serious adverse events (SAEs) were collected routinely at 6 monthly visits for a median of about 5 years in a wide range of patients with CKD who were distributed among 18 countries worldwide.

\section{Methods}

Details of the SHARP trial objectives, design, and methods have been reported previously in accordance with the CONSORT guidelines $[9,10]$. The SHARP trial was carried out in accordance with the Declaration of Helsinki.

\section{Recruitment}

People aged 40 years and older were eligible to participate if they had CKD with more than one previous measurement of serum or plasma creatinine of at least $150 \mu \mathrm{mol} / \mathrm{L}$ $(1.7 \mathrm{mg} / \mathrm{dL})$ in men or $130 \mu \mathrm{mol} / \mathrm{L}(1.5 \mathrm{mg} / \mathrm{dL})$ in women, or were receiving maintenance dialysis. Participants with prior MI or coronary revascularization were excluded. Potentially eligible participants attended a screening visit at which medical history, including history of diabetes, was recorded and written informed consent obtained. After 6 weeks of placebo run-in, participants who remained willing and eligible, had taken at least $90 \%$ of the run-in treatment, and who were thought likely to be able to attend study clinics for at least 4 years were randomized in a 4:4:1 ratio to simvastatin $20 \mathrm{mg}$ plus ezetimibe $10 \mathrm{mg}$ daily versus matching placebo combination therapy versus simvastatin $20 \mathrm{mg}$ alone. Participants who were allocated simvastatin only were re-randomized after one year to simvastatin/ezetimibe vs placebo combination therapy.

\section{Follow-up and recording of SAEs}

After initial randomization, participants were followedup in study clinics at 2 and 6 months and then every 6 months for at least 4 years. At each of these visits, information was recorded on all SAEs (defined as any untoward medical occurrence that results in death; is life-threatening; requires inpatient hospitalization or results in prolongation of existing hospitalization; results in persistent or significant disability/incapacity; is a congenital anomaly/birth defect, or; is a medically important event or reaction [with the SHARP protocol specifying cancers, myopathy, rhabdomyolysis, cholecystectomy or 
complications of gallstones and hepatitis as events of particular relevance]) occurring since the last visit. Current co-medication was also recorded at all visits. The development of diabetes mellitus among participants without diabetes at baseline (a tertiary endpoint) was defined as an SAE due to diabetes or the initiation of diabetic medications in participants not known to have diabetes mellitus at randomization.

If a participant became unwilling or unable to attend the follow-up visits, information about SAEs was obtained from them (or their relative or carer) by telephone or from their own doctors until the scheduled end of the study. Local study staff then sought additional information from hospital records and other appropriate sources about all reports of SAEs that might relate to study outcomes (ie, death, MI, cardiac arrest, angina, heart failure, stroke, transient ischaemic attack, revascularization procedures, angiography, amputation, initiation of dialysis, kidney transplant, renal failure, cancer, myopathy, rhabdomyolysis, hepatobiliary or pancreatic conditions). This information was sent to the international coordinating centre for central adjudication, in accordance with pre-specified definitions, by trained clinicians who were masked to study treatment allocation. However, the majority of nonvascular outcomes were not adjudicated.

\section{Statistical analysis}

All analyses reported here are post-hoc. Intention-totreat analyses assessed the effect of allocation to simvastatin/ezetimibe on time to first SAE, with subdivision of analyses into vascular SAE (MAEs, as defined a priori $[9,10]$, plus any other vascular SAE) and non-vascular SAEs (see Additional file 1). Subsidiary analyses subdivided analyses of non-vascular SAEs by system of disease (cancer, renal, respiratory, hepatobiliary, other gastrointestinal, other medical causes, and trauma/fracture) by outcome (fatal versus non-fatal), by baseline characteristics reported previously (age, sex, prior diabetes, baseline LDL-C, body mass index [BMI], and renal status) and by baseline characteristics not previously reported (ethnicity). Further analyses explored the effect on non-vascular SAEs by duration of follow-up.

Standard log-rank methods, stratified by whether participants were initially randomized to simvastatin only or not, were used to provide estimates of average event rate ratios (RRs), associated 95\% CIs and 2-sided $p$-values, from the time of randomization to simvastatin/ezetimibe versus placebo (ie, ignoring the 168 participants who were initially randomized to simvastatin $20 \mathrm{mg}$ only and not subsequently re-randomized to simvastatin/ezetimibe versus placebo). Standard $\chi^{2}$ tests for heterogeneity (or, where appropriate, trend) were used to compare event rate ratios between subgroups. While no formal adjustment was made for the p-values, due allowance for multiple hypothesis- testing and the post-hoc exploratory nature of these analyses were made when interpreting the results. Analyses were conducted using SAS version 9.3 and $\mathrm{R}$ version 2.14.2.

\section{Results}

Nine thousand two hundred seventy participants were randomly assigned to simvastatin/ezetimibe (4650 participants) or placebo (4620 participants), with good balance achieved in measured characteristics (Table 1). Mean age at randomization was 62 years (standard deviation [SD] 12), $5800(63 \%)$ were male, $1393(15 \%)$ had a history of vascular disease, 2094 (23\%) had diabetes and mean baseline nonfasting directly measured LDL-C was 2.8 (SD 0.9) $\mathrm{mmol} / \mathrm{L}$. The majority of participants were of white ethnicity (72\%), but a substantial minority of participants were Chinese (12\%) or of other Asian ethnicity (10\%). Approximately one-third of participants were receiving maintenance dialysis at randomization. The median duration of follow-up among survivors was 4.9 years.

\section{Serious adverse events by system of disease and event outcome}

Allocation to simvastatin/ezetimibe resulted in a significant reduction in any vascular SAE (1329 [28.6\%] simvastatin/ ezetimibe vs 1450 [31.4\%] placebo; RR 0.90, 95\% CI 0.830.97; Fig. 1). There was no significant effect on the proportion experiencing at least one non-vascular SAE (3551 [76.4\%] simvastatin/ezetimibe vs 3537 [76.6\%] placebo; RR $0.99,95 \%$ CI $0.95-1.04 ; p=0.82$ ), and no significant effect on fatal or non-fatal non-vascular SAEs when subdivided into disease systems (Fig. 1). Taking all non-vascular SAEs together (fatal and non-fatal) and ignoring any correction for mutiple testing, allocation to simvastatin/ezetimibe was associated with an increased risk of endocrine SAEs (237 [5.1\%] vs 195 [4.2\%]; RR 1.21, 95\% CI 1.01-1.47), but closer examination of these endocrine SAEs by subdivision into hormonal systems revealed no significant evidence of hazard for any individual category of events: diabetes-related complications (180 [3.9\%] vs 159 [3.4\%]; RR 1.13, 95\% CI 0.91-1.40), thyroidrelated conditions (44 [0.9\%] vs 28 [0.6\%]; RR $1.55,95 \% \mathrm{CI}$ $0.98-2.46)$, adrenal disorders (5 [0.1\%] vs 4 [0.1\%]; RR 1.24 , 95\% CI $0.34-4.60)$ and other endocrine disorders (10 [0.2\%] vs 8 [0.2\%]; RR 1.24, 95\% CI 0.49-3.13). There were nominally fewer cases of non-gallstone pancreatitis among participants allocated simvastatin/ezetimibe $(12[0.3 \%]$ vs 27 [0.6\%]; RR 0.46, 95\% CI 0.25-0.86; $p=0.02$ ), and a reduction in dialysis access revisions/complications (1532 [32.9\%] vs 1629 [35.3\%]; RR 0.92, 95\% CI 0.86-0.98), but no other apparent differences for other non-vascular SAEs (Fig. 2). Among 7176 participants without diabetes at baseline, 172 [4.8\%] in the simvastatin/ezetimibe group vs 162 [4.5\%] in the placebo group developed newonset diabetes (RR 1.06, 95\% CI 0.86-1.32). 
Table 1 Baseline demographic and laboratory measurements by treatment allocation

\begin{tabular}{|c|c|c|}
\hline & $\begin{array}{l}\text { Simvastatin plus } \\
\text { ezetimibe }(n=4650)\end{array}$ & $\begin{array}{l}\text { Placebo } \\
(n=4620)\end{array}$ \\
\hline \multicolumn{3}{|l|}{ Demographics } \\
\hline Age at randomization (years) ${ }^{a}$ & $62(12)$ & $62(12)$ \\
\hline Men & $2915(63 \%)$ & $2885(62 \%)$ \\
\hline \multicolumn{3}{|l|}{ Ethnicity } \\
\hline White & $3332(72 \%)$ & $3314(72 \%)$ \\
\hline Black & $137(3 \%)$ & $127(3 \%)$ \\
\hline Chinese & $557(12 \%)$ & $563(12 \%)$ \\
\hline Other Asian & $486(10 \%)$ & $480(10 \%)$ \\
\hline Other/not specified & $138(3 \%)$ & $136(3 \%)$ \\
\hline \multicolumn{3}{|l|}{ Prior disease } \\
\hline Prior vascular disease $\mathrm{e}^{\mathrm{a}}$ & $711(15 \%)$ & $682(15 \%)$ \\
\hline Diabetes $^{a}$ & $1054(23 \%)$ & $1040(23 \%)$ \\
\hline \multicolumn{3}{|l|}{ Renal status } \\
\hline On dialysis $^{a}$ & $1534(33 \%)$ & $1491(32 \%)$ \\
\hline Haemodialysis & $1275(27 \%)$ & $1253(27 \%)$ \\
\hline Peritoneal dialysis & $259(6 \%)$ & $238(5 \%)$ \\
\hline Not on dialysis ${ }^{a}$ & $3116(67 \%)$ & $3129(68 \%)$ \\
\hline \multicolumn{3}{|l|}{ Baseline measurements } \\
\hline Total cholesterol $(\mathrm{mmol} / \mathrm{L})^{\mathrm{a}}$ & $4.88(1.20)$ & $4.90(1.17)$ \\
\hline LDL cholesterol $(\mathrm{mmol} / \mathrm{L})^{\mathrm{a}}$ & $2.77(0.88)$ & $2.78(0.87)$ \\
\hline $\mathrm{HDL}$ cholesterol $(\mathrm{mmol} / \mathrm{L})^{\mathrm{a}}$ & $1.12(0.35)$ & $1.11(0.34)$ \\
\hline Triglycerides $(\mathrm{mmol} / \mathrm{L})^{a}$ & $2.31(1.76)$ & $2.34(1.68)$ \\
\hline Body mass index $\left(\mathrm{kg} / \mathrm{m}^{2}\right)^{a}$ & $27.1(5.7)$ & $27.1(5.6)$ \\
\hline \multicolumn{3}{|l|}{ Renal function } \\
\hline $\begin{array}{l}\text { MDRD-estimated GFR } \\
\left(\mathrm{mL} / \mathrm{min} / 1.73 \mathrm{~m}^{2}\right)^{\mathrm{a}, \mathrm{b}, \mathrm{c}}\end{array}$ & $26.6(12.9)$ & $26.6(13.1)$ \\
\hline$\geq 60$ & $44(1 \%)$ & $44(1 \%)$ \\
\hline$\geq 30$ to $<60$ & $1100(37 \%)$ & $1055(35 \%)$ \\
\hline$\geq 15$ to $<30$ & $1246(41 \%)$ & $1319(44 \%)$ \\
\hline$<15$ & $613(20 \%)$ & 606 (20\%) \\
\hline Not available & 113 & 105 \\
\hline
\end{tabular}

Data are $\mathrm{n}(\%)$ or mean (SD)

MDRD Modified Diet in Renal Disease, GFR glomerular filtration rate

${ }^{a}$ Variables updated at 1 year for patients originally allocated simvastatin only who were rerandomized to simvastatin plus ezetimibe or placebo

${ }^{b}$ Percentages exclude participants for whom data were not available for that category

${ }^{{ }^{C}}$ For patients not on dialysis

\section{Non-vascular serious adverse events by baseline characteristics}

When participants were subdivided by baseline characteristics, there was no evidence of any heterogeneity (or, for a variable that could be ordered, trend) in the effect of simvastatin/ezetimibe on non-vascular SAEs (Additional file 2: Figure S1). In particular there was no evidence of heterogeneity in the effect of simvastatin/ezetimibe on non- vascular SAEs either overall or by system of disease between patients on dialysis at randomization and those not (Additional file 2: Figure S2).

\section{Non-vascular serious adverse events by duration of follow-up}

There was no evidence of any trend toward an increasing (or decreasing) risk ratio for non-vascular SAEs with increasing duration of follow-up, either for non-vascular death (trend $\chi_{1}^{2}=1.69 ; p=0.19$ ) or for non-fatal non-vascular SAEs (trend $\chi_{1}^{2}=0.05 ; p=0.83$ ) (Additional file 2: Figure S3).

\section{Discussion}

In SHARP, simvastatin/ezetimibe resulted in a significant reduction in MAEs amongst participants with moderate to advanced CKD, with no excess risk of any of the prespecified safety outcomes $[9,10]$. The present subsidiary analyses indicate that treatment was not associated with an overall excess risk of non-vascular SAEs, and nor was there any evidence that non-vascular SAEs were increased among particular subgroups of participant defined by baseline characteristics including age, sex, diabetes, baseline LDL-C, BMI, ethnicity, and renal status.

Despite the addition of pancreatitis to the postmarketing experience section of the simvastatin/ezetimibe drug label as a potential undesirable effect [29], we observed, if anything, a reduction in non-gallstone pancreatitis events among those assigned to simvastatin/ezetimibe in SHARP, but the relevance of our findings is unclear due to the small numbers of events. A reduction in dialysis access revisions or complications was also observed, but in previous exploratory analyses, this finding was not confirmed in data from the AURORA trial, suggesting that any benefits of lowering LDL-C on vascular access patency are likely to be modest [30].

Allocation to simvastatin/ezetimibe in SHARP was associated with a marginally increased risk of endocrine SAEs overall (237 [5.1\%] vs 195 [4.2\%]; RR 1.21, 95\% CI 1.01-1.47) but such a difference is also consistent with the play of chance given the number of tests performed. Moreover, closer examination of these endocrine SAEs by subdivision into hormonal systems revealed no significant evidence of hazard.

Meta-analyses of randomized trials have shown that statin therapy is associated with approximately a 10 to $20 \%$ proportional increase in the risk for developing diabetes, equating to approximately 1 to 2 additional cases per 1000 person-years of statin treatment in those trials [13-15]. This increased risk is thought to be related to LDL receptor-mediated transmembrane cholesterol transport [31], and is supported by evidence from Mendelian randomization studies of various LDL-C targets [32-34]. The observed non-significant $6 \%$ excess 


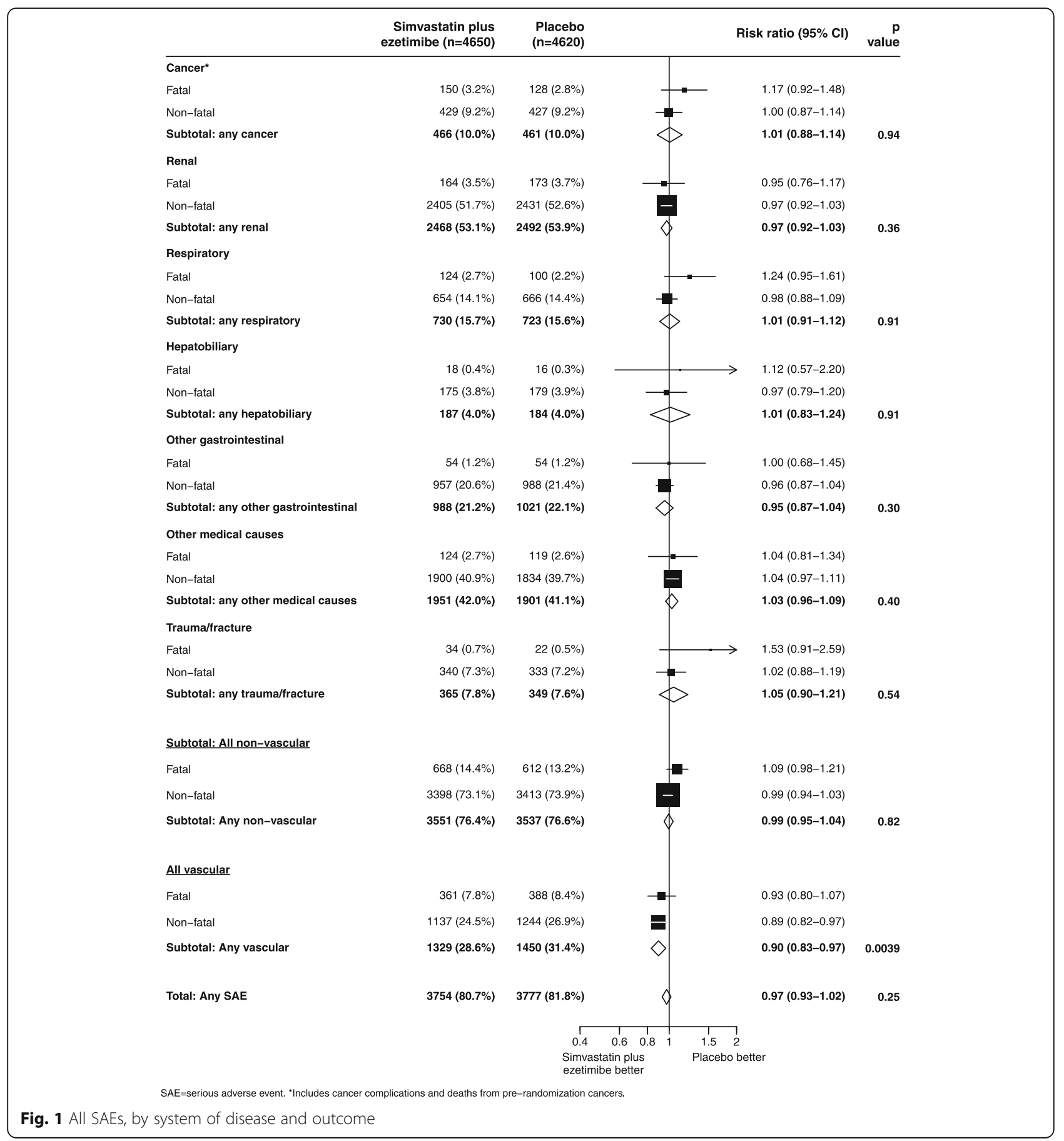

risk of diabetes seen in SHARP was consistent with these previous results, although there was limited power to assess whether the treatment effect differed from that observed in previous trials of a statin.

Some observational studies have found an inverse relationship between cholesterol levels and infectious disease $[35,36]$, leading some to suggest that lowering LDL-C may be harmful. In contrast, other studies have postulated that statins are potentially protective against infection, particularly respiratory infections [22, 23, 37], whilst randomized controlled trials in sepsis-associated acute respiratory distress syndrome and in chronic obstructive pulmonary disease have demonstrated no therapeutic benefit [38-40]. In SHARP, there were no significant effects of simvastatin/ezetimibe on the risk of infection (urinary tract, respiratory, gastrointestinal or skin). The inverse relationship between cholesterol levels and infectious disease seen in observational studies may 


\begin{tabular}{|c|c|c|c|c|c|}
\hline & & $\begin{array}{r}\text { Simvastatin plus } \\
\text { ezetimibe }(n=4650)\end{array}$ & $\begin{array}{l}\text { Placebo } \\
(n=4620)\end{array}$ & Risk ratio $(95 \% \mathrm{Cl})$ & $\begin{array}{r}p \\
\text { value }\end{array}$ \\
\hline & Any cancer $\mathrm{SAE}^{\star}$ & $466(10.0 \%)$ & $461(10.0 \%)$ & $1.01(0.88-1.14)$ & 0.94 \\
\hline & Acute-on-chronic renal failuret & $209(6.7 \%)$ & $231(7.4 \%)$ & $0.91(0.75-1.09)$ & \\
\hline & Uraemic SAE & $1584(34.1 \%)$ & $1554(33.6 \%)$ & $1.01(0.94-1.08)$ & \\
\hline & Dialysis access revision/complication & $1532(32.9 \%)$ & $1629(35.3 \%)$ & $0.92(0.86-0.98)$ & \\
\hline & Urinary tract disorder & $234(5.0 \%)$ & $229(5.0 \%)$ & $1.02(0.85-1.22)$ & \\
\hline & Urinary tract infection & $244(5.2 \%)$ & $230(5.0 \%)$ & $1.06(0.88-1.27)$ & \\
\hline & Other renal SAE & $674(14.5 \%)$ & $639(13.8 \%)$ & $1.06(0.95-1.18)$ & \\
\hline & Any renal SAE & $2468(53.1 \%)$ & $2492(53.9 \%)$ & $0.97(0.92-1.03)$ & 0.36 \\
\hline & Respiratory infection & $546(11.7 \%)$ & $506(11.0 \%)$ & $1.08(0.96-1.22)$ & \\
\hline & COPD/asthma & $70(1.5 \%)$ & $65(1.4 \%)$ & $1.07(0.77-1.50)$ & \\
\hline & Other respiratory SAE & $221(4.8 \%)$ & $249(5.4 \%)$ & $0.88(0.74-1.06)$ & \\
\hline & Any respiratory SAE & $730(15.7 \%)$ & $723(15.6 \%)$ & $1.01(0.91-1.12)$ & 0.91 \\
\hline & Hepatitis & $21(0.5 \%)$ & $18(0.4 \%)$ & $1.16(0.62-2.18)$ & \\
\hline & Other liver SAE & $35(0.8 \%)$ & $29(0.6 \%)$ & $1.20(0.74-1.97)$ & \\
\hline & Gallstones and associated complications & $111(2.4 \%)$ & $109(2.4 \%)$ & $1.01(0.78-1.32)$ & \\
\hline & Non-gallstone pancreatitis & $12(0.3 \%)$ & $27(0.6 \%) \longleftarrow$ & $0.46(0.25-0.86)$ & \\
\hline & Other hepatobiliary SAE & $40(0.9 \%)$ & $46(1.0 \%)$ & $0.87(0.57-1.32)$ & \\
\hline & Any hepatobiliary SAE & $187(4.0 \%)$ & $184(4.0 \%)$ & $1.01(0.83-1.24)$ & 0.91 \\
\hline & Upper gastrointestinal SAE & $275(5.9 \%)$ & $305(6.6 \%)$ & $0.90(0.76-1.05)$ & \\
\hline & Lower gastrointestinal SAE & $356(7.7 \%)$ & $356(7.7 \%)$ & $0.99(0.86-1.15)$ & \\
\hline & Gastrointestinal haemorrhage & $100(2.2 \%)$ & $99(2.1 \%)$ & $1.00(0.76-1.33)$ & \\
\hline & Gastrointestinal infection & $290(6.2 \%)$ & $312(6.8 \%)$ & $0.92(0.79-1.08)$ & \\
\hline & Other gastrointestinal SAE & $288(6.2 \%)$ & $296(6.4 \%)$ & $0.97(0.82-1.14)$ & \\
\hline & Any gastrointestinal SAE & $988(21.2 \%)$ & $1021(22.1 \%)$ & $0.95(0.87-1.04)$ & 0.30 \\
\hline & Skin infection & $94(2.0 \%)$ & $90(1.9 \%)$ & $1.04(0.78-1.39)$ & \\
\hline & Other skin SAE & $164(3.5 \%)$ & $166(3.6 \%)$ & $0.98(0.79-1.22)$ & \\
\hline & Any skin SAE & $242(5.2 \%)$ & $245(5.3 \%)$ & $0.98(0.82-1.17)$ & 0.85 \\
\hline & Any reproductive $\mathrm{SAE}$ & $176(3.8 \%)$ & $185(4.0 \%)$ & $0.95(0.77-1.16)$ & 0.60 \\
\hline & Any psychiatric SAE & $76(1.6 \%)$ & $77(1.7 \%)$ & $0.99(0.72-1.35)$ & 0.93 \\
\hline & Any neurological SAE & $228(4.9 \%)$ & $227(4.9 \%)$ & $1.00(0.83-1.20)$ & 1.00 \\
\hline & Myopathy & $9(0.2 \%)$ & $5(0.1 \%)$ & $1.76(0.62-5.03)$ & \\
\hline & Rhabdomyolysis & $4(0.1 \%)$ & $1(0.0 \%)$ & $3.31(0.57-19.11)$ & \\
\hline & Other musculoskeletal SAE & $488(10.5 \%)$ & $478(10.3 \%)$ & $1.02(0.90-1.15)$ & \\
\hline & Any musculoskeletal SAE & $497(10.7 \%)$ & $483(10.5 \%)$ & $1.03(0.91-1.16)$ & 0.68 \\
\hline & Any haematological SAE & 226 (4.9\%) & $205(4.4 \%)$ & $1.10(0.91-1.33)$ & 0.32 \\
\hline & Any ophthalmic SAE & $184(4.0 \%)$ & $179(3.9 \%)$ & $1.02(0.83-1.25)$ & 0.84 \\
\hline & Any ENT SAE & $72(1.5 \%)$ & $84(1.8 \%)$ & $0.85(0.62-1.17)$ & 0.32 \\
\hline & Diabetes related complications $\ddagger$ & $180(3.9 \%)$ & $159(3.4 \%)$ & $1.13(0.91-1.40)$ & \\
\hline & Other endocrine disorder & $58(1.2 \%)$ & $39(0.8 \%)$ & $1.47(0.99-2.19)$ & \\
\hline & Any endocrinology SAE\$ & $237(5.1 \%)$ & $195(4.2 \%)$ & $1.21(1.01-1.47)$ & 0.04 \\
\hline & Any other medical SAE & $942(20.3 \%)$ & $947(20.5 \%)$ & $0.99(0.91-1.09)$ & 0.88 \\
\hline & Any trauma SAE & $365(7.8 \%)$ & $349(7.6 \%)$ & $1.05(0.90-1.21)$ & 0.54 \\
\hline & Total: any non-vascular SAE & $3551(76.4 \%)$ & $3537(76.6 \%)$ & $0.99(0.95-1.04)$ & 0.82 \\
\hline & & & $\begin{array}{lll}0.4 & 0.6 & 0.8 \\
\text { Simvastatin plus } \\
\text { ezetimibe better }\end{array}$ & $\begin{array}{c}1.52 \\
\text { Placebo better }\end{array}$ & \\
\hline & 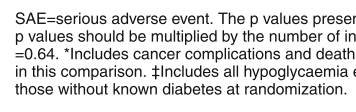 & $\begin{array}{l}\text { ed in this figure have not been } \\
\text { eependent tests conducted. For } \\
\text { from ret-randomization cance } \\
\text { rents. Sincludes } 139 \text { vs } 101 \text { an }\end{array}$ & $\begin{array}{l}\text { adjusted for multiple testing. To appl } \\
\text { example, the p value for any endocri } \\
\text { ers. }+3116 \text { s } 3129 \text { particiants not } \\
\text { nong those with known diabetes at ra }\end{array}$ & 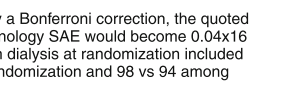 & \\
\hline Fig. 2 All non-vas & cular SAEs, by system of disease & with sub-categorie & & & \\
\hline
\end{tabular}

therefore reflect reverse causality, since people with CKD are often sick and malnourished (and hence have a lower LDL-C) and are also more prone to infections.

Studies of statins have postulated both protective effects for statins against renal progression [41] and possible nephrotoxic effects $[17,19,42]$. Previously reported analyses from SHARP showed no significant reductions in any of the pre-specified measures of renal disease progression (end-stage renal disease defined as commencement of maintenance dialysis or transplantation) [9], and exploratory analyses showed no effect on urinary albumin creatinine ratio at 2.5 years [43]. Thus whilst approximately $7 \%$ of participants not on dialysis at randomization developed acute on chronic renal failure, there was no evidence of an increased risk with simvastatin/ezetimibe.

A strength of the analyses described in this paper is that they are based on randomized assessment of treatment effects as opposed to inference from observational 
data (which can be subject to bias) [13]. However, a limitation is that they are only based on an average of five years' follow-up, so that longer-term effects cannot be quantified. Long-term follow-up of efficacy and safety in randomized trials of statins in other populations has demonstrated continuing benefits on vascular events and reassuring safety for non-vascular events (including cancer) [44, 45]. Such post-trial follow-up is therefore now underway in the SHARP cohort. Furthermore, although SHARP is the largest randomized trial in CKD patients to date, it lacks statistical power to examine rare events or certain non-vascular events in detail (such as diabetes). The reliable assessment of any such nonvascular effects is best done through large-scale metaanalyses, such as those which will be conducted by the Cholesterol Treatment Trialists' Collaboration [46]. Another possible limitation of these analyses is that the majority of non-vascular outcomes were not verified by clinician adjudicators. However, similar intention-totreat analyses of non-adjudicated, non-vascular SAEs have previously been used to demonstrate both known and previously unrecognised hazards of niacin in the large-scale HPS2-THRIVE trial [47].

\section{Conclusions}

In SHARP, simvastatin/ezetimibe did not result in any significant adverse effect on non-vascular events during a median of about 5 years' treatment among patients with CKD. These findings add to the safety information from the IMPROVE-IT trial which compared simvastatin/ezetimibe to simvastatin monotherapy in approximately 18,000 participants with acute coronary syndrome, and which therefore assessed the safety of ezetimibe when added to statin therapy. IMPROVE-IT reported no meaningful differences between the treatment groups in adverse events (including cancer, non-vascular mortality and muscle, gallbladder, hepatic and new onset diabetes adverse events) [48, 49]. The results of SHARP and IMPROVE-IT taken together therefore indicate that adding ezetimibe to simvastatin is both effective and generally well-tolerated.

\section{Additional files}

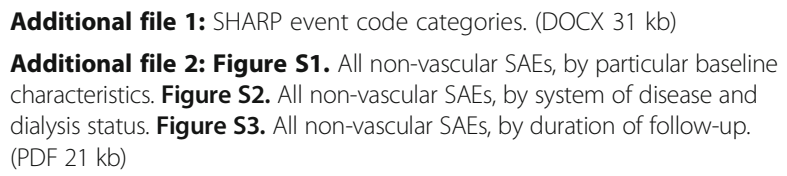

\section{Abbreviations}

BMI: Body mass index; Cl: Confidence interval; CK: Creatine kinase; CKD: Chronic kidney disease; CONSORT: CONsolidated Standards of Reporting Trials; CVD: Cardiovascular disease; GFR: Glomerular filtration rate; HPS2-THRIVE: Heart Protection Study2-Treatment of HDL to Reduce the Incidence of Vascular Events; IMPROVE-IT: Improved Reduction of Outcomes: Vytorin Efficacy International Trial; ISCRTN: International Standard Randomised
Controlled Trial Number; LDL-C: Low density lipoprotein cholesterol; MAE: Major atherosclerotic event; MDRD: Modified Diet in Renal Disease; MI: Myocardial infarction; RR: Rate ratio; SAE: Serious adverse event; SAS: Statistical Analysis System; SD: Standard deviation; SHARP: Study of Heart and Renal Protection; ULN: Upper limit of normal

\section{Acknowledgements}

We thank the participants, the local clinical centre staff, regional and national coordinators, steering committees, and data monitoring committee.

\section{Funding}

SHARP was funded by Merck \& Co., Inc., Whitehouse Station, NJ USA, with additional support from the Australian National Health Medical Research Council, the British Heart Foundation, and the UK Medical Research Council. SHARP was initiated, conducted, and interpreted independently of the principal study funder (Merck \& Co., Inc.). The Clinical Trial Service Unit \& Epidemiological Studies Unit, (CTSU), which is part of the University of Oxford, receives core funding from the UK Medical Research Council, the British Heart Foundation and Cancer Research UK.

\section{Availability of data and materials}

Access to the SHARP trial data is coordinated through the Richard Doll Centenary Archive of the Nuffield Department of Population Health, University of Oxford (https://www.ndph.ox.ac.uk/about/rdcadataaccessandsharingpolicy 2016-09-23.pdf). Requests for data access and sharing should be made by e-mail to richard.doll.archive@ndph.ox.ac.uk.

\section{Authors' contributions}

Study design: CR, NS, WGH, JE, CB, MJL; data acquisition: CR, WGH, MM, AC, L, CB, MLL; data analysis: NS, WS, JE; drafting of initial manuscript: CR; data interpretation, presentation of results and/or revision of manuscript: $\mathrm{CR}, \mathrm{NS}, \mathrm{WGH}, \mathrm{WS}, \mathrm{JE}, \mathrm{RH}$ MM, JA, AC, JCC, $\sqcup, T P, C B, M J L$. All authors approved the final manuscript.

\section{Competing interests}

Personal financial disclosures: CTSU (C Reith, N Staplin, WG Herrington, W Stevens, R Haynes, J Emberson, M Mafham, J Armitage, C Baigent and MJ Landray) has a staff policy of not accepting honoraria or other payments from the pharmaceutical industry, expect for the reimbursement of costs to participate in scientific meetings. A Cass declares no personal relationships such as employment contracts, consultancies, advisory boards, speaker bureaus, membership of Board or Directors, or stock ownership, but MSD Australia provided a small non-directed research grant to his institution, used towards filming a documentary to raise awareness regarding kidney disease amongst Indigenous Australians. TR Pedersen declares receiving research grants, consulting fees, and speaker honoraria from Merck, Pfizer, AstraZeneca and Amgen, and speaker honoraria from Sanofi-Aventis. L Jiang and J Craig declare no competing interests.

\section{Consent for publication}

Not applicable since no details relating to individual participants.

\section{Ethics approval and consent to participate}

This study involved the use of an existing dataset that contained only non-identifiable data. In the original SHARP study, ethical approval was obtained at all SHARP study sites before enrolment, and written informed consent was obtained for all SHARP participants.

\section{Publisher's Note}

Springer Nature remains neutral with regard to jurisdictional claims in published maps and institutional affiliations.

\section{Author details}

${ }^{1}$ Nuffield Department of Population Health (NDPH), University of Oxford, Oxford, UK. ${ }^{2}$ Medical Research Council-Population Health Research Unit (MRC-PHRU), NDPH, University of Oxford, Oxford, UK. ${ }^{3}$ Menzies School of Health Research, Charles Darwin University, Darwin, Australia. ${ }^{4}$ Sydney School of Public Health, University of Sydney, Sydney, Australia. ${ }^{5}$ Cardiovascular Institute and Fuwai Hospital, Chinese Academy of Medical Sciences, Beijing, China. ${ }^{6}$ Centre of Preventive Medicine, Oslo University Hospital, Oslo, Norway. ${ }^{7}$ Faculty of Medicine, University of Oslo, Oslo, Norway. 


\section{Received: 24 August 2016 Accepted: 1 April 2017}

\section{Published online: 01 May 2017}

\section{References}

1. Cholesterol Treatment Trialists' (CTT) Collaboration. Efficacy and safety of cholesterol-lowering treatment: prospective meta-analysis of data from 90056 participants in 14 randomised trials of statins. Lancet. 2005;366(9493):1267-78.

2. Cholesterol Treatment Trialists' (CTT) Collaboration. Efficacy and safety of more intensive lowering of LDL cholesterol: a meta-analysis of data from 170000 participants in 26 randomised trials. Lancet. 2010;376(9753):1670-81.

3. Cholesterol Treatment Trialists' (CTT) Collaboration. Lack of effect of lowering LDL cholesterol on cancer: meta-analysis of individual data from 175,000 people in 27 randomised trials of statin therapy. PLoS One. 2012;7(1):e29849.

4. Cholesterol Treatment Trialists' (CTT) Collaborators. Efficacy of cholesterollowering therapy in 18686 people with diabetes in 14 randomised trials of statins: a meta-analysis. Lancet. 2008;371(9607):117-25.

5. Cholesterol Treatment Trialists' (CTT) Collaboration. The effects of lowering LDL cholesterol with statin therapy in people at low risk of vascular disease: meta-analysis of individual data from 27 randomised trials. Lancet. 2012;380(9841):581-90.

6. Gansevoort RT, Correa-Rotter R, Hemmelgarn BR, Jafar TH, Heerspink HJ, Mann JF, Matsushita K, Wen CP. Chronic kidney disease and cardiovascular risk: epidemiology, mechanisms, and prevention. Lancet. 2013;382(9889):339-52.

7. Fellstrom BC, Jardine AG, Schmieder RE, Holdaas H, Bannister K, Beutler J, Chae DW, Chevaile A, Cobbe SM, Gronhagen-Riska C, et al. Rosuvastatin and cardiovascular events in patients undergoing hemodialysis. N Engl J Med. 2009;360(14):1395-407.

8. Wanner C, Krane V, Marz W, Olschewski M, Mann JF, Ruf G, Ritz E. Atorvastatin in patients with type 2 diabetes mellitus undergoing hemodialysis. N Engl J Med. 2005;353(3):238-48.

9. The SHARP Collaborative Group. The effects of lowering LDL cholesterol with simvastatin plus ezetimibe in patients with chronic kidney disease (Study of Heart and Renal Protection): a randomised placebo-controlled trial. Lancet. 2011;377(9784):2181-92.

10. The SHARP Collaborative Group. Study of Heart and Renal Protection (SHARP): randomized trial to assess the effects of lowering low-density lipoprotein cholesterol among 9,438 patients with chronic kidney disease. Am Heart J. 2010;160(5):785-94. e710.

11. Law M, Rudnicka AR. Statin safety: a systematic review. Am J Cardiol. 2006;97(8A):52C-60.

12. Armitage J. The safety of statins in clinical practice. Lancet. 2007;370(9601):1781-90

13. Collins R, Reith C, Emberson J, Armitage J, Baigent C, Blackwell L et al. Interpretation of the evidence for the efficacy and safety of statin therapy. Lancet 2016; 388: 2532-61.

14. Preiss D, Seshasai SR, Welsh P, Murphy SA, Ho JE, Waters DD, DeMicco DA, Barter P, Cannon CP, Sabatine MS, et al. Risk of incident diabetes with intensive-dose compared with moderate-dose statin therapy: a meta-analysis JAMA. 2011;305(24):2556-64.

15. Sattar N, Preiss D, Murray HM, Welsh P, Buckley BM, de Craen AJ, Seshasai SR, McMurray JJ, Freeman DJ, Jukema JW, et al. Statins and risk of incident diabetes: a collaborative meta-analysis of randomised statin trials. Lancet. 2010;375(9716):735-42.

16. The Stroke Prevention by Aggressive Reduction in Cholesterol Levels (SPARCL) Investigators. High-dose atorvastatin after stroke or transient ischemic attack. N Engl J Med. 2006;355(6):549-59.

17. Hippisley-Cox J, Coupland C. Unintended effects of statins in men and women in England and Wales: population based cohort study using the QResearch database. BMJ. 2010;340:c2197.

18. Bjornsson E, Jacobsen El, Kalaitzakis E. Hepatotoxicity associated with statins: reports of idiosyncratic liver injury post-marketing. J Hepatol. 2012;56(2):374-80.

19. Dormuth $C R$, Hemmelgarn BR, Paterson JM, James MT, Teare GF, Raymond CB, Lafrance JP, Levy A, Garg AX, Ernst P, et al. Use of high potency statins and rates of admission for acute kidney injury: multicenter, retrospective observational analysis of administrative databases. BMJ. 2013;346:f880.

20. Evans MA, Golomb BA. Statin-associated adverse cognitive effects: survey results from 171 patients. Pharmacotherapy. 2009;29(7):800-11.

21. Takada M, Fujimoto M, Yamazaki K, Takamoto M, Hosomi K. Association of statin use with sleep disturbances: data mining of a spontaneous reporting database and a prescription database. Drug Saf. 2014;37(6):421-31.
22. van de Garde EM, Hak E, Souverein PC, Hoes AW, van den Bosch JM, Leufkens HG. Statin treatment and reduced risk of pneumonia in patients with diabetes. Thorax. 2006;61(11):957-61.

23. Khan AR, Riaz M, Bin Abdulhak AA, Al-Tannir MA, Garbati MA, Erwin PJ, Baddour LM, Tleyjeh IM. The role of statins in prevention and treatment of community acquired pneumonia: a systematic review and meta-analysis. PLoS One. 2013;8(1):e52929.

24. Atar S, Cannon CP, Murphy SA, Rosanio S, Uretsky BF, Birnbaum Y. Statins are associated with lower risk of gastrointestinal bleeding in patients with unstable coronary syndromes: analysis of the Orbofiban in Patients with Unstable coronary Syndromes-Thrombolysis In Myocardial Infarction 16 (OPUS-TIMI 16) trial. Am Heart J. 2006;151(5):976 e971-976.

25. Wahner AD, Bronstein JM, Bordelon YM, Ritz B. Statin use and the risk of Parkinson disease. Neurology. 2008;70(16 Pt 2):1418-22.

26. Lee YC, Lin CH, Wu RM, Lin MS, Lin JW, Chang CH, Lai MS. Discontinuation of statin therapy associates with Parkinson disease: a population-based study. Neurology. 2013:81(5):410-6.

27. Chan KA, Andrade SE, Boles M, Buist DSM, Chase GA, Donahue JG, Goodman MJ, Gurwitz JH, LaCroix AZ, Platt R. Inhibitors of hydroxymethylglutaryl-coenzyme A reductase and risk of fracture among older women. Lancet. 2000;355(9222):2185-8.

28. de Jager DJ, Grootendorst DC, Jager KJ, van Dijk PC, Tomas LM, Ansell D, Collart F, Finne P, Heaf JG, De Meester J, et al. Cardiovascular and noncardiovascular mortality among patients starting dialysis. JAMA. 2009;302(16):1782-9.

29. Inegy tablets; Summary of Product Characteristics. https://www.medicines. org.uk/emc/medicine/15657\#PRODUCTINFO. Accessed 11 Apr 2017.

30. The SHARP Collaborative Group. The effect of lowering LDL cholesterol on vascular access patency: post hoc analysis of the Study of Heart and Renal Protection. Clin J Am Soc Nephrol 2014: 9(5) 914-919.

31. Besseling J, Kastelein JJ, Defesche JC, Hutten BA, Hovingh GK. Association between familial hypercholesterolemia and prevalence of type 2 diabetes mellitus. JAMA. 2015;313(10):1029-36.

32. Ference BA, Robinson JG, Brook RD, Catapano AL, Chapman MJ, Neff DR, Voros S, Giugliano RP, Davey Smith G, Fazio S, et al. Variation in PCSK9 and HMGCR and Risk of Cardiovascular Disease and Diabetes. N Engl J Med. 2016:375(22):2144-53.

33. Schmidt AF, Swerdlow DI, Holmes MV, Patel RS, Fairhurst-Hunter Z, Lyall DM, Hartwig FP, Horta BL, Hypponen E, Power C, et al. PCSK9 genetic variants and risk of type 2 diabetes: a mendelian randomisation study. Lancet Diabetes Endocrinol. 2017;5(2):97-105. doi:10.1016/S2213-8587(16)30396-5.

34. Lotta LA, Sharp SJ, Burgess S, Perry JR, Stewart ID, Willems SM, Luan J, Ardanaz E, Arriola L, Balkau B, et al. Association between low-density lipoprotein cholesterol-lowering genetic variants and risk of type 2 diabetes: a meta-analysis. JAMA. 2016;316(13):1383-91.

35. Iribarren C. Cohort study of serum total cholesterol and in-hospital incidence of infectious diseases. Epidemiol Infect. 1998;121:335-47.

36. Iribarren C, Jacobs Jr DR, Sidney S, Claxton AJ, Gross MD, Sadler M, Blackburn H. Serum total cholesterol and risk of hospitalization, and death from respiratory disease. Int J Epidemiol. 1997;26(6):1191-202.

37. Frost FJ, Petersen H, Tollestrup K, Skipper B. Influenza and COPD mortality protection as pleiotropic, dose-dependent effects of statins. Chest. 2007;131(4):1006-12.

38. National Heart Lung Blood Institute ARDS Clinical Trials Network. Rosuvastatin for sepsis-associated acute respiratory distress syndrome. N Engl J Med. 2014;370(23):2191-200

39. Criner GJ, Connett JE, Aaron SD, Albert RK, Bailey WC, Casaburi R, Cooper Jr JA, Curtis JL, Dransfield MT, Han MK, et al. Simvastatin for the prevention of exacerbations in moderate-to-severe COPD. N Engl J Med. 2014; 370(23):2201-10.

40. McAuley DF, Laffey JG, O'Kane CM, Perkins GD, Mullan B, Trinder TJ, Johnston P, Hopkins PA, Johnston AJ, McDowell C, et al. Simvastatin in the acute respiratory distress syndrome. N Engl J Med. 2014;371(18):1695-703.

41. Fried LF, Orchard TJ, Kasiske BL. Effect of lipid reduction on the progression of renal disease: a meta-analysis. Kidney Int. 2001;59(1):260-9.

42. Zheng Z, Jayaram R, Jiang L, Emberson J, Zhao Y, Li Q, Du J, Guarguagli S, Hill M, Chen Z, et al. Perioperative Rosuvastatin in Cardiac Surgery. N Engl J Med. 2016;374(18):1744-53.

43. The SHARP Collaborative Group. Effects of lowering LDL cholesterol on progression of kidney disease. J Am Soc Nephrol. 2014;25(8):1825-33.

44. Bulbulia R, Bowman L, Wallendszus K, Parish S, Armitage J, Peto R, Collins R. Effects on 11-year mortality and morbidity of lowering LDL cholesterol with 
simvastatin for about 5 years in 20,536 high-risk individuals: a randomised controlled trial. Lancet. 2011;378(9808):2013-20.

45. Ford I, Murray H, McCowan C, Packard CJ. Long-term safety and efficacy of lowering low-density lipoprotein cholesterol with statin therapy: 20-year follow-up of west of Scotland coronary prevention study. Circulation. 2016;133(11):1073-80.

46. Cholesterol Treatment Trialists' (CTT) Collaboration. Protocol for analyses of adverse event data from randomized controlled trials of statin therapy. Am Heart J. 2016;176:63-9.

47. HPS2-THRIVE Collaborative Group. Effects of extended-release niacin with laropiprant in high-risk patients. N Engl J Med. 2014;371(3):203.

48. Cannon CP, Blazing MA, Giugliano RP, McCagg A, White JA, Theroux P, Darius H, Lewis BS, Ophuis TO, Jukema JW, et al. Ezetimibe added to statin therapy after acute coronary syndromes. N Engl J Med. 2015;372:2387-97.

49. Merck Sharp and Dohme. IMPROVE-TT Study. Food and Drug Administration Endocrinologic and Metabolic Drug Products Advisory Committee Briefing Document. 2015. https:/www.fda.gov/downloads/AdvisoryCommittees/ CommitteesMeetingMaterials/Drugs/EndocrinologicandMetabolicDrugs AdvisoryCommittee/UCM476506.pdf. Accessed 30 Mar 2016.

\section{Submit your next manuscript to BioMed Central} and we will help you at every step:

- We accept pre-submission inquiries

- Our selector tool helps you to find the most relevant journal

- We provide round the clock customer support

- Convenient online submission

- Thorough peer review

- Inclusion in PubMed and all major indexing services

- Maximum visibility for your research

Submit your manuscript at www.biomedcentral.com/submit 